\title{
OS DIREITOS AUTORAIS DIANTE DA DISPONIBILIDADEDAS OBRAS AUDIOVISUAIS TRANSMITIDAS PELA NETFLIX
}

\author{
Valter Moura do Carmo ${ }^{1}$ \\ Gleissa Mendonça Faria Cardoso ${ }^{2}$
}

\begin{abstract}
RESUMO:
O presente estudo teve por escopo examinar como são disponibilizadas as obras audiovisuais transmitidas pela Netflix em observância aos direitos autorais e se existe violação desses direitos pelo cliente desse serviço. Como metodologia utilizada, optou-se pelo método dedutivo com o uso de doutrina específica nas áreas de novas tecnologias e de propriedade intelectual. Ao final ficou demonstrado que a Netflix é uma TV por internet que compra a licença dos filmes e séries. E o sistema streaming impossibilita a violação dos direitos autorais pelos usuários em razão da natureza do sistema, que utiliza a transmissão online, ou seja, as informações não são armazenadas pelo usuário em seu aparelho eletrônico.
\end{abstract}

Palavras-chave: Direitos Autorais. Internet. Netflix. Sistema streaming. TV por internet.

\section{COPYRIGHT IN VIEW OF THE AVAILABILITY OF AUDIOVISUAL WORKS ON NETFLIX}

\begin{abstract}
:
The objective of this study is to examine how audiovisual works transmitted by Netflix are made available in compliance with copyright law, and if there is a violation of these rights by the clients of that service. In terms of methodology, the deductive method was chosen with the use of specific scholarship in the fields of new technologies and intellectual property. We demonstrate that Netflix is an Internet TV that buys the license of films and series, and that the streaming system precludes copyright infringement by users. This is so because of the nature of the system, which uses online transmission, that is, the information is not stored by the user on his electronic device.
\end{abstract}

Keywords: Copyright. Internet. Netflix. Streaming system. Internet TV.

\footnotetext{
${ }^{1}$ Possui graduação em Direito pela Universidade de Fortaleza; mestrado em Direito Constitucional pela Universidade de Fortaleza com período sanduíche na Universidade Federal de Santa Catarina - UFSC e doutorado em Direito pela UFSC, tendo realizado o doutorado sanduíche na Universidade de Zaragoza (Espanha) com bolsa do PDSE da CAPES e período de investigação na Universidade Federal da Paraíba - UFPB com bolsa do PROCAD da CAPES. Diretor de eventos do CONPEDI e coordenador científico do Seminário Internacional Diálogo Ambiental, Constitucional e Internacional. Membro da Comissão de Estudo de Identificação e Descrição da ABNT. Tem experiência na área de Direito, com ênfase em Direito Constitucional, Direito Internacional e Direitos Humanos. Editor-Adjunto da Revista Argumentum (Marília), Revista de Pesquisa e Educação Jurídica e da Revista do Instituto Brasileiro de Direitos Humanos.

${ }^{2}$ Advogada, Graduada em Direito pelo ILES/ Ulbra em Itumbiara/GO, Especialista em Direito de Família pela Universidade Cândido Mendes, Mestranda em Direito pela UNIMAR em Marília/ São Paulo. Técnica em Enfermagem pelo Colégio Sena Aires em Itumbiara/GO, Especialização profissional de nível técnico em Enfermagem do Trabalho pelo Projeção-Central de Ensino do Triângulo em Uberlândia/MG.
} 


\section{INTRODUÇÃO}

O Direito está em constante mutação e adequação com a realidade social. Não se pode omitir o caráter dinâmico do ordenamento jurídico, posto que em cada momento histórico os valores eleitos pela sociedade se alteram, sendo incorporados novos conceitos, princípios e características. A globalização e os avanços tecnológicos estão presentes no cotidiano das pessoas e um setor que vem aclamando por regulamentações e proteções jurídicas é o de tecnologia digital, principalmente as mídias áudio visuais e sua disponibilidade desenfreada pelo mercado over the top, causando uma insegurança no que se refere aos direitos autorais do autor.

Em razão das diversas complexidades da vida contemporânea, tornaram-se a interpretação, julgamento e amparo dos direitos autorais um grande desafio. Na era analógica, era possível fazer uma reprodução não autorizada de obras de terceiros com uma qualidade mais precária e com valor mais acessível em relação ao produto original, no entanto, nem todos tinham acesso a essas cópias. Mas durante o progredir do século, notadamente com o nascimento do mundo digital e com o acessível contato da internet, foi propiciada a facilidade de acessar, reproduzir e alterar obras de terceiros, sem observância aos direitos autorais.

Nesse sentido, este trabalho científico apresenta como tema: "Os direitos autorais diante da disponibilidade das obras audiovisuais transmitidas pela Netflix". O presente estudo teve por escopo examinar se a Netflix tem licença dos direitos autorais das obras audiovisuais transmitidas em seu sistema streming e se os seus clientes violam esses direitos ao reproduzir o conteúdo em seus aparelhos pessoais. Tem-se como objetivo geral pesquisar como são disponibilizadas as obras audiovisuais transmitidas pela Netflix em observância aos direitos autorais e se existe violação desses direitos pelo usuário desse serviço. Dando sequência, tem como objetivos específicos expor sobre a evolução da comunicação e transmissões de informações; conceituar direitos autorais e o sistema streaming e, por fim, verificar os direitos autorais na disponibilidade das obras audiovisuais da Netflix e se existe violação desses direitos pelo cliente.

Nesta pesquisa foi utilizada a metodologia bibliográfica, utilizando-se do método dedutivo, o qual parte de uma ideia geral para uma ideia particular, partindo de estudos e análises de teorias e leis para explicações de fenômenos particulares. Foram utilizadas 
também fontes primárias e secundárias, pois se optou por usar doutrinas, leis, jurisprudências e artigos científicos.

Justifica-se a relevância deste, em decorrência, do surgimento das novas tecnologias como Netflix e congêneres que fomentam o mercado de uma forma instantânea, impactando diretamente na economia e no Direito. Dessa forma, faz-se importante identificar como essa nova classe de serviços está inserida legalmente no ordenamento jurídico, mais especificamente em relação aos direitos autorais das obras disponibilizadas pela Netflix.

\section{CONSIDERAÇÕESSOBRE A EVOLUÇÃO DA COMUNICAÇÃO E TRANSMISSÕ̃ES DE INFORMAÇÕES}

O ser humano, desde os primórdios, tem a necessidade de comunicar-se e viver em grupo, isso ocorria por instinto de sobrevivência e como solução para ajudá-lo a enfrentar os desafios da natureza. Devido a essa sociabilidade natural, surgiu o importante e necessário ato de comunicar-se, pois a linguagem era imprescindível para o entendimento entre as pessoas. A linguagem era baseada na voz, gestos, sinais, sons e desenhos, os homens não conheciam a escrita e a pintura rupestre era uma dessas formas de comunicar-se, não existia uma padronização na forma na comunicação.

A invenção da escrita surgiu em consequência do desenvolvimento da comunicação e das mudanças nas sociedades durante o surgimento das primeiras cidades. Por volta de 3.300 a.C., pelo menos quatro sistemas de escrita foram inventados, de forma independente e em épocas diferentes, por quatro regiões distintas, Mesopotâmia, Egito, China e América Central. A partir de então, tanto a escrita evoluiu em estilos e tamanhos quanto os suportes usados para ela também: barro, madeira, metal, tecido, couro, papiro etc., até a chegada do papel (BATALHA, 2017).

Podemos considerar que o surgimento da escrita teve um papel fundamental na preservação e construção de registros históricos para as atuais e futuras gerações e, ainda, foi a pioneira no surgimento de transmissão de informações e na construção do conhecimento humano.

Um fato que marcou a explosão cultural foi à invenção de Gutemberg, no século XV, a imprensa. Sua descoberta impulsionou e provocou profundas e amplas mudanças na ordem do mundo, seja no setor religioso, político, econômico, social e cultural, que foram desencadeados simultaneamente ao surgimento da imprensa (NEVES, 2001). 
Devido à invenção da impressão, cuja principal característica é a divulgação de comunicação em massa por meio de livros, jornais, entre outros, começaram a surgir inúmeros problemas no tocante à proteção jurídica do direito autoral, ou seja, questionamentos sobre a remuneração dos autores e de seus direitos de reproduzir e de disponibilizar suas obras.

Após a grande repercussão da impressão, surge uma outra inovação tecnológica, o telégrafo óptico desenvolvido por Claude Chappe, no final do século XVIII, era como uma comunicação de leitura a distância através de códigos. Em seguida, ocorreu a invenção do telefone, por Alexander Graham Bell em 1876. No início do século XX, surgiram outras inovações que também foram essenciais para a evolução da comunicação, notadamente, a televisão, o cinema falado, o gravador, a caneta esferográfica, a fotocopiadora e os primeiros computadores e seus suportes (DIAS, 1999).

O gradativo crescimento tecnológico que ocorreu no decorrer dos séculos, possibilitou um grande aumento do conhecimento e alcance das informações, a tecnologia vem se expandindo vorazmente. Está presente no cotidiano de todos, e tem-se consolidado como um bem essencial, útil e valioso para evolução e relacionamento do homem, especialmente no que refere ao surgimento da internet como uma tecnologia inovadora nas relações sociais e profissionais.

\subsection{INTERNET: UMA TECNOLOGIA INOVADORA}

Nas últimas décadas, a influência da tecnologia cresceu assustadoramente, trabalhos monótonos que demandavam muito tempo para serem executados agora, em questão de segundos são concluídos, atos complexos são agora facilitados pela informatização, gerando maior facilidade, celeridade e efetividade no nosso cotidiano social e profissional.

A transição do mundo analógico para o digital foi considerada uma importante evolução, no entanto não é fácil, tampouco simples, realizar essas transformações, como digitalizar filmes e gravações anteriormente gravadas em fitas cassetes e DVD para serem transmitidos e armazenados em formato digital, ou ainda, digitalizar músicas que no passado eram gravadas em Discos e CDs.

A história da internet no Brasil começou por volta dos anos 90, considerada um conjunto de computadores integrados que possuía protocolos e serviços em comum. Para 
melhor elucidação da evolução da internet, vejamos seu desenvolvimento, de forma resumida, no país até o ano de 1999, vejamos: 1987 - Na Universidade de São Paulo é realizada a reunião entre pesquisadores de todo País para discutir o estabelecimento de uma rede nacional para fins acadêmicos, com compartilhamento de acesso a redes internacionais, [...]. 1988 - No Rio de Janeiro, o Laboratório Nacional de Computação Científica consegue o acesso à BITNET, através de uma conexão de 9,600 bps[...]. 1990 -É fundada a Associação para o Progresso das comunicações (APC). [...]1996 - A internet cresceu demais em 96. Usuários e provedores apareceram rapidamente e isso ajudou muito a internet no Brasil. [...]. 1999 - O número de internautas já ultrapassa a marca dos 2,5 milhões. Zip Mail é o maior em seu gênero (No Brasil) mais de 2 milhões de usuários inscritos. (PORTAL, 2017).

A evolução tecnológica, resultado do processo de globalização mundial, espalha seus efeitos nas mais diversas áreas e setores. Notadamente, é um grande e eficiente instrumento de trabalho, possibilitando mais celeridade, efetividade, facilidade, armazenamento e busca de dados e, ainda, na área da educação, possibilitando maior acesso a pesquisas, estudos, entre outros.

Os avanços tecnológicos possibilitam a expansão e popularização de aparelhos eletrônicos e também atingem o setor da tecnologia de comunicação, o qual tem como objetivo melhorar, agilizar e expandir a comunicação, de maneira a atingir o telespectador de forma mais eficiente e adequada às suas expectativas.

A tecnologia digital tornou-se fundamental na vida das pessoas, devido a essa amplitude e necessidade, ambientes públicos como bares, hotéis, restaurantes e outros, têm acompanhado essa evolução tecnológica adequando seus ambientes comerciais e culturais a essa nova era, como a implantação de internet via Wi-fi livre.

A tecnologia ultrapassa fronteiras, limites territoriais, aproxima pessoas do mundo inteiro, consequentemente, surgem concomitantes as violações às liberdades individuais, sendo necessária uma proteção e intervenção do poder público. E, por todas essas razões, mostrou-se, então, necessário o desenvolvimento e adequação de um ramo do Direito que trabalhasse com essa nova realidade, notadamente os Direitos Autorais.

\section{DIREITOS AUTORAIS}


Uma das principais intenções do avanço tecnológico é a disseminação da cultura, do entretenimento e do lazer. As criações intelectuais, independentemente dos meios de comunicação pelos quais são disseminadas, como edição gráfica, produções audiovisuais ou através de computadores, devem ter suas normas jurídicas respeitadas, a fim de que se retribua dignamente o talento e os esforços desenvolvidos pelos que nelas trabalham sem o que, provavelmente, não mais se criarão novas obras.

O direito autoral apresenta essencialmente dois institutos na tutela da criação intelectual do autor: o direito moral que se refere à autoria, vinculada à maternidade da criação, que assegura ao criador a referência de seu nome em sua obra intelectual e o direito patrimonial que é direcionado ao aspecto pecuniário, ou seja, visa administrar as relações jurídicas econômicas do uso da criação intelectiva.

Desde as especulações filosóficas de Kant, o direito autoral é aquele em que o titular de uma obra tem o direito de impedir que alguém a torne pública sem sua expressa autorização. Contudo, vem-se debatendo a característica imaterial desse direito, que não teria assim muita ligação com seus aspectos materiais, mas sim com a forma de expressão das ideias, o que seria uma verdadeira transposição de personalidade dos seus criadores (GANDELMAN, 2001).

Henrique Gandelman (2001) expõe que, na era do videocassete, qualquer cidadão era um produtor cinematográfico, sem ter que arcar com despesas e nem pagar nada aos legítimos produtores, escritores e roteiristas, diretores, autores, músicos, cinegrafistas, técnicos, etc. $\mathrm{Na}$ verdade, o combate à pirataria atualmente é uma batalha internacional, considerada a própria defesa do direito à autoria, a continuidade do direito à criação e, portanto, um dos direitos humanos fundamentais.

Desde os anos 80, já havia preocupações referentes à pirataria de filmes cinematográficos em videocassetes, alguns fatores foram facilitadores para o aumento dessa prática na época, notadamente a facilidade de gravação de imagens e sons pela TV, mas o que mais atraía a prática da pirataria era a obtenção de lucro fácil, com um custo operacional baixo em relação ao produto legal, além de nada se pagar aos detentores de direitos autorais e nem mesmo impostos.

\subsection{PREVISÕES JURÍDICAS}


$\mathrm{Na}$ contemporaneidade, depara-se com uma alarmante realidade de pirataria na internet envolvendo os direitos autorais do autor. É o que acontece na era virtual, os direitos do autor cada vez mais estão sendo violados e por mais esforços desprendidos para coibir essa situação, não se conseguem grandes resultados, pois as leis não conseguem acompanhar a acelerada evolução da tecnologia da informação.

Segundo Zygmund Bauman (2007, p.10), as pessoas "vivem em uma sociedade de valores voláteis, descuidada do futuro, egoísta e hedonista. Veem as novidades como inovações, a precariedade como um valor, a instabilidade como imperativo, o hibridismo como riqueza". Para o autor, no atual contexto histórico presencia-se uma sociedade instável, que insaciavelmente anseia por novidades e, ainda descomprometida com o futuro, busca suprir apenas seus próprios prazeres. Em consequência desse perfil de pessoas, faz-se necessário o legislador se atentar a adequar às normas jurídicas o atual modelo de sociedade.

Na proteção dos direitos autorais, a Declaração Universal dos Direitos Humanos consagra em seu artigo 27:

1.Toda a pessoa tem o direito de tomar parte livremente na vida cultural da comunidade, de fruir as artes e de participar no progresso científico e nos benefícios que deste resultam.

2.Todos têm direito à proteção dos interesses morais e materiais ligados a qualquer produção científica, literária ou artística da sua autoria (BRASIL, 2017).

O citado artigo 27 enfatiza o acesso aos direitos culturais e ainda a proteção do DUDH do direito do autor no âmbito moral e material, entendendo-se por moral aqueles ligados à autoria da obra e resultado de sua atividade criativa.

Atualmente, a Lei 9.610 de 19/02/1998versasobre os Direitos Autorais. Existem dois tipos de sanções que penalizam esses tipos de crimes no âmbito civil e penal, a lei 9.610/1998 determina nos arts. 102 a 110 as sanções civis cabíveis neste tipo de crime de violação do direito autoral. No âmbito penal, em seu artigo $184^{3}$, versa sobre a violação dos direitos de autor e os que lhe são conexos.

Ainda na intenção de tutelar esse direito privado, a Constituição Federal da República Brasileira de 1988 também trouxe em rol direitos e garantias fundamentais, como se lê no artigo $5^{\circ}$, incisos IX, XXVII e XXVIII.

\footnotetext{
${ }^{3}$ Art. 184. Violar direitos de autor e os que lhe são conexos: $\S 1^{\circ}$ Se a violação consistir em reprodução total ou parcial, com intuito de lucro direto ou indireto, por qualquer meio ou processo, de obra intelectual, interpretação, execução ou fonograma, sem autorização expressa do autor, do artista intérprete ou executante, do produtor, conforme o caso, ou de quem os represente: Pena - reclusão, de 2 (dois) a 4 (quatro) anos, e multa (...). BRASIL. Código Penal. Dec. Lei n ${ }^{\circ}$ 2.848/1940. 2a ed. São Paulo: Revista dos Tribunais, 2015.
} 
IV - é livre a manifestação do pensamento, sendo vedado o anonimato; (...),

XXVII - aos autores pertence o direito exclusivo de utilização, publicação ou reprodução de suas obras, transmissível aos herdeiros pelo tempo que a lei fixar; XXVIII - são assegurados, nos termos da lei: a) a proteção às participações individuais em obras coletivas e à reprodução da imagem e voz humanas, inclusive nas atividades desportivas; b) o direito de fiscalização do aproveitamento econômico das obras que criarem ou de que participarem aos criadores, aos intérpretes e às respectivas representações sindicais e associativas.

Na contemporaneidade, o grande desafio para o direito autoral sem dúvida é o acelerado avanço da tecnologia diante de obras até então protegidas e que ficam disponibilizadas publicamente de forma desenfreada e incontrolável. O desafio será em adaptar o desenvolvimento tecnológico e moderno às leis que garantem a proteção necessária aos autores no exercício de seus direitos perante suas criações. Nesse sentido, as instituições responsáveis em regular, fiscalizar, arrecadar e distribuir os direitos autorais são: ECAD E ANCINE.

\subsection{ECAD (ESCRITÓRIO CENTRAL DE ARRECADAÇÃO E DISTRIBUIÇÃO).}

O ECAD é uma entidade privada, criada pela lei 5.988 de 1973, seu âmbito de atuação é, no tocante aos direitos autorais relacionados à execução pública musical, o ECAD é o responsável por concentrar a arrecadação e fazer à devida distribuição dos valores arrecadados as associações que em seguida repassam aos artistas filiados.

Entretanto, proveniente de constantes contrariedades de executores, intérpretes, artistas, entre outros empresários, resultaram denúncias por apropriação indébita, entre outras irregularidades por parte de administradores do ECAD e, nos anos de 1995, 2011 e 2012, foram objeto de CPI (Comissão Parlamentar de Inquérito). Devido a inúmeros problemas que impregnavam o setor, além de críticas a LDA n ${ }^{\circ}$ 9.610/1998, foi criada a Lei 12.853/2013, que prevê novas regras referentes à gestão coletiva de direitos autorais (CUNHA FILHO; TELLES; COSTA, 2015, p.101).

De acordo com as Leis Federais 9.610/1998 e 12.853/2013 que regulamentam os direitos autorais, apenas ao autor é conferido o direito de usar, fruir, e dispor de sua obra, bem como permitir ou impedir a sua utilização por terceiros, independentemente se a utilizar no todo ou não. Em observância a essas leis, organizadores de eventos, televisão, rádio, cinema, entre outros estabelecimentos comerciais, que reproduzam som musical ambiente, têm o dever 
de efetuar o pagamento dos direitos autorais pelas músicas que são usadas publicamente (ECAD, 2017).

O Superior Tribunal de Justiça unificou que "a transmissão de músicas mediante o emprego da tecnologia streaming na modalidade simulcasting constitui meio autônomo de uso de obra intelectual, caracterizando novo fato gerador de cobrança de direitos autorais pelo ECAD”. Verifica-se que, surge uma nova modalidade de cobrança dos direitos do autor, e mesmo que se utilize a tecnologia streaming de transmissão online, não exime o pagamento desses direitos junto ao ECAD.

\subsection{ANCINE (AGÊNCIA NACIONAL DO CINEMA).}

Criada em 2001 pela Medida Provisória 2228-1, a ANCINE é uma agência reguladora que tem como atribuições o fomento, a regulação e a fiscalização do mercado do cinema e do audiovisual no Brasil. É uma autarquia especial, vinculada desde 2003 ao Ministério da Cultura, com sede e foro no Distrito Federal e Escritório Central no Rio de Janeiro.

A missão da ANCINE é desenvolver e regular o setor audiovisual em benefício da sociedade brasileira. Encerrado o ciclo de sua implementação e consolidação, a ANCINE enfrenta agora o desafio de aprimorar seus instrumentos regulatórios, atuando em todos os elos da cadeia produtiva do setor, incentivando o investimento privado, para que mais produtos audiovisuais nacionais e independentes sejam vistos por um número cada vez maior de brasileiros (ANCINE, 2017).

\section{O SISTEMA STREAMING}

Niklas Luhmann (1985, p. 7-12) afirma que o direito moderno se caracteriza pelo contínuo processo de mudança em seus conteúdos, motivo pelo qual pode ser visto como instrumento de mudança planificada de uma realidade cada vez mais complexa, o que se observa no caso da regulamentação das novas tecnologias como os serviços streaming.

A inclusão digital permitirá, num curto espaço de tempo, contabilizar para a rede resultados ainda mais interessantes: o eventual barateamento do computador, as ousadas investidas da telefonia, a crescente aceitação do comércio eletrônico e a adoção da classe $\mathrm{C}$, entre outros, projetarão a internet numa dimensão maior, 
tornando-a ainda mais dinâmica, eficaz e eficiente enquanto canal de comunicação (FRANZÃO, 2006, p. 37).

Notadamente, essas novas tecnologias fizeram uma verdadeira revolução nas relações pessoais e comerciais por transmitir informações de forma global e em tempo real, no que tange à tradicional compra e venda de produtos, mas também em relação a novos serviços oferecidos, como por exemplo, os aplicativos de comunicação, as redes sociais e os serviços de transmissão de dados e vídeos.

O cenário do setor audiovisual está em constante mudança, especialmente diante dos grandes e frequentes avanços tecnológicos, cujos efeitos afetam diretamente a produção e transmissão dos produtos finais desse setor, não se restringindo somente aos aspectos informáticos e eletrônicos, isto é, à expansão e popularização dos smartphones, tablets, laptops etc.

Constantemente, as pessoas vêm trocando a versão física pela online para obter informações ou entretenimento, mas por trás dessa opção se deparam com várias controvérsias e complexidades. Nesse sentido cabe aqui uma breve explicação sobre streaming:

Streaming é uma técnica que permite a transmissão de informação multimídia através de uma rede de computadores concomitantemente com o consumo desta informação multimídia por parte do usuário. Em outras palavras, enquanto o usuário assiste a um vídeo, as próximas cenas estão sendo transmitidas. Deste modo, o usuário começa a assistir a um vídeo sem antes ter que baixá-lo integralmente. Aplicações de streaming de vídeo possibilitam a transmissão de vídeo ao vivo e também de vídeos maiores sem que o usuário tenha que armazená-los ou esperar muito tempo para começar a assisti-los (CLEMENTE, 2006, p. 1).

Alonso (2017) também define streaming e faz uma ilustração sobre o seu funcionamento conforme figura abaixo:

El streaming es una tecnología que permite La distribuición de archivos multimedia a través de La redsin esperas ya que se estandes cargando al mismo tiempo que los visualiza. Los usuários pueden pedir el contenido deseado em cualquier momento, ya que el streaming es uma corriente continuada que fluyes ininterrupción (ALONSO, 2017).

Segundo pesquisa da Accenture, o Brasil possui, proporcionalmente, maior número de consumidores que consomem vídeos pela internet do que a média mundial, superando nações como Estados Unidos, Reino Unido e Espanha (ACCENTURE, 2011). 
Dessa forma, a televisão e sua programação sequenciada entram em decadência em face da distribuição de conteúdo por streaming, que oferece filmes e programas de televisão em catálogos para que, assim, o telespectador possa escolher o que assistir com vastas quantidades de filmes em seus catálogos. Inclusive com serviços que adequam as recomendações aos gostos dos telespectadores, ou seja, quando quiser,não há hora certa ou exclusiva para determinada transmissão, quer seja via tablet, smartphone, laptop, televisão e aonde quiser, seja, na espera de um fila, em automóveis, esperando determinado atendimento médico ou na sua própria casa.

\subsection{O SISTEMA STREMING E A PIRATARIA DIGITAL}

Para alguns estudiosos essa nova tecnologia streaming utilizada pela Netflix é uma alternativa ao combate a violações de direitos autorais oriundas da pirataria digital como baixar livros, músicas, filmes, protegidos pelos direitos do autor.

Bibiana Biscaia Virtuoso (2015, p.1) corrobora sobre o Streaming e pirataria digital:

O streaming pode vir a ser uma alternativa para brigar contra a pirataria, contudo, ainda é necessário desenvolver uma forma que permita o contentamento dos usuários e autores. $\mathrm{O}$ sistema atual ainda possui brechas que podem prejudicar os dois lados. Se for garantido os direitos autorais, ao mesmo tempo em que se mantém as mensalidades acessíveis, a pirataria pode ser controlada. As pessoas poderão deixar de baixar arquivos ilegalmente para terem acesso a um acervo grande e de qualidade

Esses argumentos da inovação tecnológica do streaming contribuir na luta contra a pirataria é em razão de sua própria natureza, pois o usuário não faz download do conteúdo e devido ao baixo custo do serviço, como, por exemplo, a Netflix.“Atualmente, serviços de vídeo ondemand, como a Netflix, têm contribuído bastante para diminuir a incidência da pirataria ao oferecer diversas opções de entretenimento por um preço acessível" (BLOG, 2015).

\section{O SURGIMENTO E O VORAZ AVANÇO DA NETFLIX}

Em 1997 surgiu a Netflix, fundada por Reed Hastings e Marc Randolph.Inicialmente ela surgiu como um serviço online de locação de filmes. Apenas em 2007 iniciou o serviço de 
transmissão online, que permitia aos assinantes assistir a séries e filmes instantaneamente no computador. E em2016ocorreu a sua expansão por todo o mundo (NETFLIX, 2017a).

Segundo o contrato social levado a registro perante a Junta Comercial do Estado de São Paulo (2017), a empresa "Netflix Entretenimento Brasil Ltda.”, possui como objeto social o desenvolvimento de portais, provedores de conteúdo e outros serviços de informação na internet, bem como de tratamento de dados, provedores de serviços de aplicação e de hospedagem na internet.

Atualmente, a empresa Netflix é pioneira no ramo de TV por internet no mundo, alcançando mais de 190 países, e uma estimativa de mais de 100 milhões de assinantes, assistindo a filmes, séries e documentários, contabilizando mais de 125 milhões/horas/dia (NETFLIX, 2017a). Entre os benefícios dos assinantes de tipo de serviço de transmissão por fluxo contínuo, está a possibilidade de assistir à quantidade de filmes e séries que desejar, com a comodidade de assistir à hora e onde for favorável ao assinante, utilizando qualquer tela com conexão à Internet, desde que seja compatível com o provedor streaming. Além, ainda, de poder assistir, pausar e retornar ao conteúdo escolhido, sem comerciais e sem nenhum tipo de interrupção.

O modo linear de programação em que o telespectador tem que assistir na hora certa e data exata da exibição de algum filme ou programa de televisão, bem como o aluguel de filmes em locadoras, perde lugar para o conteúdo de vídeo (on-demand) sob demanda. Neste, o telespectador assiste o que quer, como quer, quando quer e onde quiser, de acordo com a sua vontade e não de certa emissora de televisão.

A Netflix é um serviço de assinatura online que oferece para aos assinantes acesso a filmes, séries e outros produtos de entretenimento audiovisual transmitidos pela Internet para televisores, computadores e outros aparelhos conectados à Internet. O software de transmissão online (streaming) da Netflix foi desenvolvido pela ou para a Netflix e foi projetado para permitir a transmissão online de conteúdo da Netflix para aparelhos compatíveis com a Netflix. Esse software poderá variar conforme o aparelho e mídia. Para utilizar o serviço Netflix é necessário ter acesso à Internet, escolher o plano de assinatura, fornecer uma forma de pagamento em dia, inclusive planos ou assinaturas promocionais, com diferentes condições e limitações. 


\subsection{A REGULAMENTAÇÃO DA NETFLIX}

O atual cenário político e social conturbado desencadeou debates quanto às alterações legislativas no âmbito cultural, em especial na importância de proteção das obras intelectuais, "bem como dos benefícios e conflitos gerados pelas transformações permanentes ocasionadas pelas novas tecnologias da informação e da comunicação" (CUNHA FILHO; TELLES; COSTA, 2015, p. 100). Acentua a necessidade de instituir instrumentos jurídicos para equilibrar e regular as relações que envolvem os bens culturais.

Cunha Filho sugere que uma saída para resolver esses conflitos seria concentrar em dois instrumentos antes usados pelo sistema normativo autoral, "a ampliação das limitações a fim de deixar previstos novos usos razoáveis surgidos a partir desta era da sociedade da informação" (CUNHA FILHO; TELLES; COSTA, 2015, p. 115). Fazer alterações que não afetam a exploração econômica da obra, ou seja, não prejudiquem o direito patrimonial, no entanto, sem deixar em uma situação de insegurança jurídica os usuários e criadores.

Atualmente, no entanto, precisa ser reanalisado e adaptado aos novos alcances oriundos do extraordinário impacto das sofisticadas e modernas tecnologias criadas pela comunicação de massa.

Sob a óptica do ordenamento jurídico brasileiro, inexiste classificação expressa sobre o tema. Há, no entanto, cláusulas abertas que acolhem o modelo de negócio de vídeo por demanda, por meio de interpretação evolutiva, como ocorre, por exemplo, no caso da ANCINE que possui a competência de atualizar as definições por ela utilizadas, em consonância com a evolução tecnológica (SILVA, 2017, p.1).

Se há um lugar onde o conceito de revolução constante pode ser aplicado inteiramente é o do desenvolvimento da tecnologia da informação. Mal a sociedade brasileira teve tempo de celebrar a aprovação do Marco Civil da Internet em 2014, um novo desafio se estabeleceu: a regulação do mercado Over The Top (OTT), que consiste no fornecimento de conteúdo audiovisual e também de outras mídias via internet.

O presidente da Ancine, Manoel Rangel, manifestou que no Brasil e na Europa estão em discussão sobre a criação de um marco regulatório para o setor de vídeo sob demanda, e que está ainda sob polêmica. A TV paga pressiona a Ancine para exigir de empresas como Netflix isonomia tributária de serviços e conteúdo, e cotas mínimas de obras nacionais no catálogo (ANCINE, 2016).

Em contato pelo e-mail da Ancine com escritório regional em São Paulo,escritorio.sp@ancine.gov.br, no dia 15 de dezembro de 2016, foi informado que a 
ANCINE, agência reguladora federal, tem estudado a regulamentação de serviços de Video on Demand (VoD), como a Netflix e outros.

Recentemente, no dia 14 dezembro de 2016, o Senado aprovou um projeto de lei que estende a lista de serviços que são tributados, com alíquota de $2 \%$, com o Imposto Sobre Serviços de Qualquer Natureza (ISS). O projeto foi aprovado, por 63 votos a favor e 3 contra, sendo assim, todos os serviços de streaming de áudio e vídeo, como Netflix e Spotify, passarão a pagar o imposto. De acordo com o texto do projeto de lei, a "disponibilização, sem cessão definitiva, de conteúdos de áudio, vídeo, imagem e texto por meio da internet" passarão a ter incidência de ISS (MANS, 2017).

\subsection{OS DIREITOS AUTORAIS NA DISPONIBILIDADE DAS OBRAS AUDIOVISUAIS DA NETFLIXE A REPRODUÇÃO DESSAS OBRAS PELO CLIENTE}

Estamos vivendo na contemporaneidade uma explosão tecnológica, a era da comunicação em massa, de transmissão de informações instantânea e uma crescente ambição por mais e mais tecnologias. Essa crescente busca por avanços tecnológicos se faz presente em diversos setores, notadamente, na disponibilidade de obras cinematográficas pelo sistema OTT (Over The Top). Mas em confronto a esse avanço desacerbado fica a problemática sobre como são disponibilizadas as obras cinematográficas pela Netflix em observância ao Direito Autoral Brasileiro e a reprodução pelos clientes caracterizaria cópia ilegal.

A tecnologia streaming usada pela Netflix é uma "corrente, fluxo, transmissão online", tendo como objetivo permitir que um usuário reproduza conteúdos protegidos por direitos de autor na internet, sem a violação desses direitos, sendo que as informações não são armazenadas pelo usuário em seu próprio computador. Com isso, o usuário não faz o download do conteúdo, fato esse que configuraria a cópia ilegal, bem como não a utiliza através de execução pública e nem por fim comercial, já que, via de regra, reproduz o conteúdo para seu pessoal (TANGERINO, 2017).

Dessa forma, os protagonistas dessa relação saem beneficiados, ao final, visto que os assinantes usufruem de conteúdos de alta qualidade, com fácil acesso, com maior comodidade, baixos custos de transação e sem empregar meios ilícitos e imorais para tal; o detentor do direito autoral terá sua propriedade intelectual respeitada e remunerada; e o fornecedor do serviço passa a explorar uma nova modalidade de mercado lucrativa e, a princípio, bem recepcionada (VIERA, 2015). 
O serviço Netflix e todo o conteúdo visualizado por intermédio do serviço Netflix destina-se exclusivamente para uso pessoal e não comercial. Durante sua assinatura Netflix, a Netflix concede a você uma licença limitada, não exclusiva e não transferível para acessar o serviço Netflix e assistir ao conteúdo da Netflix. Com exceção à licença limitada descrita acima, nenhum outro direito, titularidade ou participação lhe é concedido (NETFLIX, 2017b).

No caso da Netflix, ela possui a licença de uso das obras transmitidas em seu sistema. A licença representa uma autorização por parte do autor para que terceiro se valha da obra, com exclusividade ou não, nos termos da autorização concedida (BRANCO JUNIOR, 2017). Ou seja, a licença, nada mais é que a uma locação (se onerosa) ou um comodato (se gratuita).

Consta nos termos de adesão ao serviço Netflix que: Direitos autorais. O serviço Netflix, incluindo todo o conteúdo fornecido pelo serviço Netflix, é protegido por direitos autorais, segredos comerciais e outras leis e tratados de propriedade intelectual (NETFLIX, 2017b).

O presidente da Netflix explica que as séries de TV só são licenciadas para empresas como Netflix depois de exibidas na TV (e remuneradas via publicidade). A Netflix é uma TV por internet, compra a licença das produções, trabalha com licenças de filmes por períodos e por regiões, quando um contrato termina, renova-se, o que faz o filme nem chegar a sair do catálogo (PETRÓ, 2012).

Segundo informações sobre como é feita a disponibilização de obras fornecidas pela Netflix, pelo número 0800-887-0201, se obteve a seguinte resposta: "a Netflix utiliza tecnologias para verificar a localização geográfica dos usuários, e assim, disponibilizar os filmes e séries de acordo com a licença que possui de cada país, ou seja, os filmes e séries mudam nos catálogos de acordo com o país".

Ou seja, a Netflix trabalha com provedores, distribuidores, produtores e criadores de conteúdo para adquirir licenças de filmes e séries e disponibilizá-los em seu serviço. Ainda nesse sentido, foram obtidas outras informações pelo Bate-Papo da Netflix:

\footnotetext{
A disponibilização dos conteúdos funciona da seguinte forma... Como a NETFLIX trabalha com licenças de reprodução, então fazemos uma espécie de contrato com a produtora por um determinado tempo. A produtora que nos dá o pacote completo do conteúdo, como legendas, dublagens... E principalmente ela que determina a data de estreia aqui na NETFLIX. Dependemos totalmente da produtora do conteúdo" (NETFLIX, 2017c)
}

Segundo dados fornecidos pelo autoatendimento Netflix: 


\begin{abstract}
A Netflix é um serviço de streaming de televisão, dedicado a filmes e séries. Ativo desde 2007 nos EUA, é o líder mundial do serviço de televisão via internet, com mais de 65 milhões de subscritores em mais de 50 países. Por uma mensalidade, o utilizador acessa aos conteúdos oferecidos pelo serviço, que é distribuído via internet. Basicamente, através do Netflix poderá ver filmes e séries quando quiser (on demand), a Netflix não tem permanentemente os direitos de nenhum filme ou série, a não ser de suas produções próprias. Isso quer dizer que os contratos são feitos entre a Netflix e as detentoras dos direitos de exibição, e esses contratos têm data de validade definida. No caso das series, esse acordo é feito por temporada e vamos até as produtoras e compramos os direitos de exibição dos conteúdos, essas licenças podem variar de acordo com as leis e regimentos de cada país (NETFLIX, 2017c).
\end{abstract}

Enfim, as obras disponibilizadas pela Neflix são obras licenciadas, uma espécie de contrato com a produtora por um determinado tempo, podendo variar de acordo com regimentos e leis de cada lugar. Dessa forma, os assinantes, usufruem de conteúdos de alta qualidade; o detentor do direito autoral tem sua propriedade intelectual respeitada e remunerada e a Netflix exibe as obras de uma forma legal e lucrativa, através da tecnologia streaming, não havendo informações de download para um disco local, pois as informações são enviadas através da rede e o usuário assiste em tempo real quando as recebe.

\title{
CONCLUSÃO
}

Um novo conceito de serviços de entretenimento que ganha cada dia mais adeptos no Brasil é a Netflix. Considerado um serviço com software de transmissão online (streaming), conceito dos mais modernos em prestação de serviços de TV pela internet. A Netflix se caracteriza por disponibilizar aos seus clientes, que pagam uma taxa mensal acessível para utilização do serviço de transmissão de filmes e séries disponíveis em um provedor, que poderá ser acessado através da internet quando, como, o que e onde quiser, conforme seu desejo.

O que interessa, porém, para o meio jurídico, é identificar como essa nova classe de serviços está inserida legalmente no ordenamento jurídico, notadamente, identificar como funcionam os Direitos Autorais na disponibilidade das obras audiovisuais transmitidas pela Netflix e se a transmissão dessas obras pelo cliente viola esses direitos. Dessa forma, compreender melhor esse enquadramento e, a partir daí, entender como funciona esta prestação de serviços e de que forma ela ocorre.

A partir do presente estudo foi possível uma reflexão acerca de questões evolvendo os Direitos Autorais, as novas tecnologias streaming, bem como a disponibilidade das obras 
da Netflix. É por meio dessas novas tecnologias que ocorre a mudança de paradigma, surgindo novas relações comerciais, proporcionando a difusão instantânea de novos conhecimentos, produtos e informações, surgindo questionamentos quanto aos Direitos Autorais das obras disponibilizadas na Netflix em face do processo de globalização e facilidade dos usuários que possuem internet.

Assim, surge a importância da regulação e também da compra da licença das produções exibidas pela Netflix, para que dessa forma todos saiam beneficiados, tanto os assinantes que usufruem de conteúdos de alta qualidade com preço baixo, quanto o detentor do direito autoral, tendo sua propriedade intelectual respeitada e remunerada e também a fornecedora do serviço que passa a explorar uma nova modalidade de mercado lucrativa e dentro da lei.

Ao final, ficou demostrado que a Netflix possui licença de uso das obras transmitidas em seu sistema, sendo os contratos feitos entre a Netflix e as detentoras dos direitos de exibição, possuindo data de validade definida, podendo ainda essas licenças variar de acordo com as leis e regimentos de cada país. Utilizam-se, para tanto, tecnologias para verificação da localização geográfica dos usuários e, de tal modo, a Netflix disponibiliza filmes e séries de acordo com a licença que possui cada país, ou seja, os filmes e séries mudam nos catálogos de acordo com a localização.

Restou concluído, ainda, que os clientes desse serviço não violam os direitos autorais ao reproduzir obras audiovisuais em seus aparelhos pessoais devido à própria natureza do sistema streaming. Porque a tecnologia streaming usada pela Netflix é uma corrente, fluxo, transmissão online, tendo como finalidade, permitir que o usuário reproduza conteúdos protegidos por direitos de autor, na internet, sem a violação desses direitos, porque as informações não são armazenadas pelo usuário em seu aparelho eletrônico. Com isso, o usuário não faz o download do conteúdo, fato esse que configuraria a cópia ilegal, bem como não a utiliza através de execução pública e nem por fim comercial, já que, em tese, reproduz as obras audiovisuais para seu pessoal.

\section{REFERÊNCIAS}

ACCENTURE. Consumers of all ages are going over-the-top: Results of the 2011. Disponível em:

$<$ http://www.accenture.com/SiteCollectionDocuments/PDF/Accenture_Communications_Me 
dia_Entertainment_Video-Over-Internet_Consumer_Usage_Survey.pdf $>$. Acesso em: 16 maio 2017.

ALONSO, Francisco José Suárez. Slides. Tecnologías de Streaming. Área de Arquitectura y Tecnología de Computadores Curso. Universidad de Oviedo. Disponível em: <https://prezi. com/zqs0ld3jauwl/tecnologias-en-streaming/>. Acesso em: 06 maio 2017.

ANCINE. Apresentação. Disponível em: <http://www.ancine.gov.br/ancine/apresentacao>. 2017. Acesso em: 24 abr. 2017.

ANCINE. Marco regulatório europeu pode ajudar a reger Netflix no Brasil. O Estado de São Paulo/SP - Caderno 2. Disponível em:

<http://www.ancine.gov.br/sites/default/files/clipping/2016-03-10-EstadodeSP-Netflix.pdf>. 2016. Acesso em: 03 mar. 2017.

BAUMAN, Zygmund. Vida Líquida. Tradução Carlos Alberto Medeiros. Rio de Janeiro: Jorge Zahar. 2007.

BATALHA, Elisa. O Abecê da escrita. In vivo. 2017. Disponível em: $<$ http://www.invivo.fiocruz.br/cgi/cgilua.exe/sys/start.htm?infoid=911\&sid=7>. Acesso em: 22 abr. 2017.

BRANCO JUNIOR, Sérgio Vieira. Direitos autorais. In: Propriedade intelectual - Roteiro de curso. Fundação Getúlio Vargas. Disponível em: <http://academico.direitorio.fgv.br/ccmw/images/2/25/Propriedade_Intelectual.pdf>. Acesso em: 01 jan. 2017.

BRASIL. Constituição da República Federal do Brasil de 1988. Brasília: Senado Federal, 1988.

BRASIL. Código Penal. Dec. Lei n ${ }^{0}$ 2.848/1940. VADE MECUM RT - 2ª ed. São Paulo: Revista dos Tribunais, 2015.

BRASIL. Declaração Universal dos Direitos Humanos. Disponível em:

<http://www.mp.go.gov.br/portalweb/hp/7/docs/declaracao_universal_dos_direitos_do_home m.pdf>. Acesso em: 01 maio 2017.

BRASIL. Lei no 9.610, de 19 de fevereiro de 1998. Disponível em:

<http://www.planalto.gov.br/ccivil_03/leis/L9610.htm>. Acesso em 20 abr. 2017.

BRASIL. Supremo Tribunal Federal/STJ. REsp 1.559.264-RJ, Rel. Min. Ricardo Villas Bôas Cueva, por maioria, julgado em 8/2/2017, DJe 15/2/2017. Disponível em:

$<$ http://www.stj.jus .br/SCON/jurisprudencia/ toc.jsp?livre=201302654647.REG.>. Acesso em: 08 maio 2017.

CLEMENTE, Ricardo Gomes. Uma solução de streaming de vídeo para celulares: conceitos, protocolos e aplicativos. Trabalho de Conclusão de Curso. Universidade Federal do Rio de Janeiro - Escola Politécnica Departamento de eletrônica e de computação, julho de 2006.

DIAS, Cláudia Augusto. Hipertexto: evolução histórica e efeitos sociais. Ci. Inf., Brasília, v. 28, n. 3, p. 269-277, 1999. Disponível em:

<http://www.scielo.br/scielo.php?script=sci_arttext\&pid=S0100-19651999000300004>. Acesso em: 10 abr. 2017. 
ECAD. Quem somos. Disponível em: <http://www.ecad.org.br/pt/o-ecad/quemsomos/Paginas/default.aspx>. Acesso em: 22 abr. 2017.

FRANZÃO, Angelo. Midialização: o poder da mídia. São Paulo: Nobel. 2006.

GANDELMAN, Henrique. A Pirataria de filmes cinematográficos em videocassetes. São Paulo: União Brasileira de Vídeo. 1989.

GANDELMAN, Henrique. De Gutemberg à Internet: direitos autorais na era digital. 4. ed. Rio de Janeiro: Record. 2001.

JUNTA COMERCIAL DO ESTADO DE SÃO PAULO. Certidão simplificada - Netflix Entretenimento Brasil Ltda. Disponível em:

<https://www.jucesponline.sp.gov.br/Pre_Visualiza.aspx?nire=35227579380\&idproduto=>.A cesso em: 20 abr. 2017

LUHMANN, Niklas. Sociologia do Direito II. Rio de Janeiro: Tempo Brasileiro. 1985.

MANS, Matheus. Netflix e Spotify passarão a pagar ISS no Brasil. Estadão Jornal Digital. Disponível em: <http://link.estadao.com.br/noticias/empresas, netflix-e-spotify-deverao-pagariss-no-brasil,10000094593 >. Acesso em: 20 mar. 2017.

NETFLIX. História da Netflix. Disponível em: <https://media.netflix.com/pt_br/aboutnetflix>. Acesso em 10 mar. 2017a.

NETFLIX. 2017. Termos de uso da Netflix. Disponível em:

<https://help.netflix.com/legal/termsofuse>. Acesso em: 14 mar. 2017b.

NETFLIX. Central de ajuda. Disponível em:

<https://help.netflix.com/pt/node/4976?catId=pt\%2F493>. Acesso em: 21 mar. 2017c.

NEVES, Teresa Cristina da Costa. Leitura e meios de comunicação. 2001. Facom/UFJF, v. 4, n.1, p.115-128. Disponível em: 〈http://www.ufjf.br/facom/files/2013/03/R6-Tereza.pdf〉. Acesso em: 04 mar. 2017.

PETRÓ, Gustavo. Brasileiros ainda não entenderam o Netflix', diz presidente da empresa.

Globo. G1. 2012. Disponível em:

<http://g1.globo.com/tecnologia/noticia/2012/08/brasileiros-ainda-nao-entenderam-o-netflixdiz-presidente-da-empresa.html>. Acesso em: 20 mar. 2017.

PORTAL São Francisco. História da internet. Disponível em:

http://www.portalsaofrancisco. com.br/alfa/historia-da-internet/historia-da-internet.php.

Acesso em: 24 abr. 2017.

CUNHA FILHO, Francisco Humberto; TELLES, Mário Ferreira Pragmácio; COSTA,

Rodrigo Vieira. Direitos Culturais no Governo Dilma: 7 Pecados do Capital, 7 Virtudes do Social. In: RUBIM, Antônio Albino Canelas et al. (Org.). Direitos Culturais no Governo Dilma. Salvador: EDUFBA, 2015. p. 97-125 (Coleção Cult).

TANGERINO, Dayane Fanti. A tecnologia streaming e a violação de direitos autorais. Canal Ciências Criminais. Disponível em: <https://canalcienciascriminais.com.br/tecnologiastreaming-e-violacao-de-direitos-autorais/>. Acesso em: 20 mar. 2017.

SILVA, Lucas do Monte. A distribuição de conteúdo por streaming: bem ou serviço cultural. Disponível em: 
<http://www.academia.edu/26703522/A_distribui\%C3\%A7\%C3\%A3o_de_conte\%C3\%BAd o_por_streaming_bem_ou_servi\%C3\%A7o_cultural>. Acesso em: 04 jan. 2017.

VIEIRA, Guilherme Siqueira. Os serviços 'over the top' como forma de combate as violações de direitos autorais oriundas da pirataria digital. Direito \& TI. 2015. Disponível em: $<$ http://direitoeti.com.br/artigos/os-servicos-over-the-top-como-forma-de-combate-asviolacoes-de-direitos-autorais-oriundas-da-pirataria-digital/>. Acesso em: 06 maio 2017.

VIRTUOSO, Bibiana Biscaia. Streaming e pirataria digital: há solução? In: GEDAI. IX CODAIP. 2015. Disponível em: <http://www.gedai.com.br/sites/default/files/ publicacoes/ anais_ix_codaip_completo.compressed.pdf $>$. Acesso em: 09 maio 2017. 